\title{
HOMEM OCIDENTAL - HOMEM ORIENTAL Community Supported agriculture como escultura social
}

\author{
Hermann Pohlmann \\ Pesquisador Científico, Universidade Münster, Alemanha
}

\section{Resumo}

Se conseguirmos transformar, também de maneira plástico-social, o espaço que os pintores paisagistas do séc. XIX prometeram como imagens de um outro mundo, então conseguiremos tornar esse mundo dos pintores paisagistas em algo que se pode vivenciar. Não como um espaço de vivência transitável, para fugir dos centros urbanos, mas para chegar a uma verdadeira obra de arte global.

Palavras Chave

Escultura social, Community Supported Agriculture, sustentabilidade sócio ambiental.

\begin{abstract}
If we can transform, so too plastic-social space that landscape painters of the century. XIX pledged as images of another world, then we can make this world of landscape painters in something you can experience. Not as a passable living space to escape from the urban centers, but to get a true work of art overall.

Keywords

Social sculpture, Community Supported Agriculture, environmental and social sustainability.
\end{abstract}

\section{Introdução}

Um organismo social vivo é mais do que a soma de todos os seus membros, desde que cada um se esforce de maneira sincera para trazer as suas capacidades para a comunidade. Esse esforço de cada um realiza-se por meio de educação e autoeducação: “... nós continuamos a aprender e não vamos parar de aprender.” (Craemer, 1987) 
A Community Supported Agriculture (CSA) é uma agricultura sustentada pela comunidade. Nesse conceito, o agricultor deixa de vender seus produtos por meio de intermediários e conta, para a organização e financiamento de sua produção, com a participação de membros consumidores, colaborando para o desenvolvimento sustentável da região e estimulando um comércio justo. Todos os custos de marketing são eliminados. Assim, os consumidores e os produtores podem juntos criar uma "agricultura" alimentar, compartilhando tanto as suas responsabilidades pela produção dos alimentos, quanto pela conservação da paisagem e do solo.

Como meta espiritual, o objetivo de uma CSA é despertar, por meio de uma comunidade de produtores e consumidores, uma compreensão para a agricultura como um organismo agrícola (fazenda ou sítio). Além disso, levar os produtores a uma variedade no plantio, em um organismo agrícola onde ocorre uma comunhão entre planta e animal, ser humano e terra. Como meta social, possibilitar o acesso a um solo frutífero para todos os participantes. Como meta econômica, produzir uma variedade de produtos.

Essas metas preservam os seres humanos e o meio ambiente. CSA é menos um conceito pronto do que uma consideração básica de que todos os seres humanos deveriam ter novamente uma relação maior para com a agricultura, e assim reconhecer sua importância. Na medida em que assumem por um ano, especialmente em termos financeiros, a responsabilidade por um empreendimento agrícola concreto em sua região, os participantes do CSA desenvolvem uma compreensão para com os problemas dele. Além disso, vivenciam também o valor cultural de uma agricultura ecológica variada.

O objetivo não é somente produzir alimentos, mas também consciência. Não temos todas as respostas, mas podemos formular algumas perguntas. Como daqui em diante podemos realizar uma agricultura sustentável eficaz? Como podemos não somente preservar o solo, mas também os agricultores? A agricultura industrial não é a resposta. 
A CSA representa a possibilidade de transformar considerações teóricas em prática, nos âmbitos social, ecológico, econômico, espiritual, legal, cultural e pedagógico.

\section{A nobre arte real tornar-se-á no futuro uma arte social}

Do ponto de vista humano, recebemos cada vez mais tarefas a perder de vista. Os processos que não podem ser planejados, as perturbações constituem as tarefas do artista, do artista social. Nesse caso o artista adentra um caminho desconhecido, com infinitas possibilidades. A biografia torna-se uma viagem para o desconhecido, uma aventura; poder brincar, observar o que se desenvolve. A fantasia moral e o individualismo ético são, como método, o fundamento de uma escultura social.

Em nenhum lugar encontramos um ponto de partida tão radical para falar sobre esse individualismo ético e sobre liberdade, como na "Filosofia da Liberdade" de Rudolf Steiner (1894)i. Enquanto alguém manda em mim, não sou livre. Leis e determinações morais são faltas de liberdade, elaboradas por seres humanos que não eu próprio. Enquanto não encontro em mim essas leis, não as desenvolvo a partir de mim, atuo sem liberdade.

Para transformar nosso individualismo em uma consciência mais elevada, necessitamos de um instrumento que nos permita agir de tal modo, que nossa necessidade pelo sensorial, pela percepção por meio de nossos sentidos, seja formada de tal maneira, que "nós nos disponhamos a acolher, tal como nós mesmos teríamos produzido e a produzir, tal como o sentido só acolher." (Schiller, F) Segundo Friedrich Schiller, esse instrumento é o impulso lúdico, ou, como Rudolf Steiner o denomina, a técnica moral e a fantasia moral. O verdadeiro ser humano é um artista, pois, segundo Friedrich Schiller, "Arte e vida devem constituir uma síntese". (Steiner, R; 1989)

Necessitamos de espaços para exercitar a formação de uma tal síntese, para não permanecer simplesmente na área mental. Espaços de exercício, nos quais 
possamos aproximar-nos de maneira lúdica das tarefas que a vida nos coloca, de modo a transformar a vida numa arte do viver. Espaços, onde possamos "brincar, tanto com as nossas tendências, quanto com o nosso respeito" (Schiller, F.). Em uma Community Supported Education (CSE, educação apoiada na comunidade), temos algo semelhante a um colegiado de professores em uma escola Waldorf, no qual a trimembração do organismo social pode ser disposta de tal maneira, que no trabalho conjunto diário essa arte social pode ser exercitada na prática.

$\mathrm{Na}$ escultura social $\mathrm{o}$ ateliê situa-se entre as pessoas. No entanto, necessitamos de campos de atividades nítidos, nos quais podemos trabalhar uns com os outros de maneira igualitária. Nada de esmola, nem piedade, mas voltar a refletir sobre o ideal democrático. Uma verdadeira fraternidade entre aqueles que podem permitir-se a oferecer algo.

\title{
A tarefa é formarmo-nos como grupo
}

\begin{abstract}
"Em relação àquilo que os seres humanos produzem intelectualmente, eles não são exatamente mesquinhos, segundo sua natureza; eles desejam compartilhá-lo o máximo possível com todas as pessoas. Aquele que é apenas um poeta lírico gostaria, acima de tudo, de oferecer aquilo que ele produz a todas as pessoas generosamente e sem egoísmo e não guardá-lo para si. Em relação aos bens materiais externos, no entanto, as pessoas agem hoje em dia de outro modo: elas querem guardá-los para si. Porém estes nunca nos provém de dentro, mas são dados justamente pelo que há ao nosso redor. A arte social consistiria, pois, em transformar gradativamente de tal forma o que nos rodeia exteriormente, que o ser humano o possa tratar como aquilo que lhe é próprio desde o seu interior, como aquilo que brota totalmente de sua individualidade." (Steiner, R ;1921)
\end{abstract}

Uma escultura social já pode começar com dois seres humanos. "Pois, onde dois ou três estão reunidos em meu nome, estou em seu meio."ii (Mateus 18:20) No entanto, para se atingir uma escultura que corresponda às pretensões de uma obra de arte na qual nós, como seres humanos, somos o material e ao mesmo tempo nos inserimos com as nossas ideias, teremos que chegar a uma atenção muito elevada, com uma presença bem desperta. Se o meu querer encontra lugar no outro e o seu querer em mim, então podemos chegar a uma afinidade. Devo aceitar o outro como artista, como criador. 
"Por meio dessa arte real [segundo os conceitos da maçonaria] o ser humano deve receber algo em suas mãos, parecido com a força que germina na planta, aquela força que o mago emprega, quando ele faz crescer mais rapidamente a planta que está à sua frente. De maneira semelhante, uma parte dessa força deve ser empregada para sanar o social. Essa força, que foi descrita por aqueles que conhecem algo dos mistérios rosacruz, ... está, no entanto, atualmente ainda em um estado germinal elementar. No futuro ela será o conteúdo dos graus mais elevados da maçonaria. A nobre arte real será no futuro uma ARTE SOCIAL." (Steiner, R; 1906)

\section{O conceito do ser humano livre}

Para esse princípio revolucionário o ser humano necessita um 'instrumento, no intuito de fazer-se respeitar como artista no âmbito social: uma fantasia moral, uma técnica moral. "Cada ser humano é um artista em seu local de trabalho." (Joseph Beuys) ${ }^{\mathrm{iii}}$. Aqui a arte deve ser entendida como ampliada para uma arte social, uma escultura social. E o instrumento para o escultor social é a fantasia moral.

\begin{abstract}
"Haverá muitas pessoas que dirão: o conceito de ser humano livre que você está esboçando é uma quimera, não se concretiza em lugar algum. ... Eu não duvido disso. Somente um cego poderia fazê-lo. ... Mas os seres humanos, os de livre espírito, erguem-se em meio às ordens repressoras, aqueles que encontram a si mesmos no caos de costumes, coação de leis, exercício da religião etc. ... Quem de nós pode afirmar que é realmente livre em todas suas ações? Porém, em cada um de nós vive uma entidade mais profunda, na qual se expressa o ser humano livre. ... A natureza faz do ser humano um mero ser natural; a sociedade o faz um ser que age segundo leis; só ele próprio pode fazer de si próprio um ser livre. ... O ponto de vista da moral livre não afirma que o espírito livre é a única forma na qual um ser humano pode existir. Ela vê na espiritualidade livre somente o último estágio de desenvolvimento do ser humano. Com isso não se nega que o agir segundo normas é justificado como um passo no desenvolvimento. ... Mas o espírito livre supera as normas no sentido de que ele não sente somente preceitos como motivos, mas orienta o seu agir segundo os seus impulsos (intuições)..." (Steiner, R : 1988, 94)
\end{abstract}

"A fantasia moral é, portanto, o que o espírito livre necessita para concretizar suas ideias, para se afirmar. Ela é a fonte para a atuação do espírito livre. ... A atuação moral pressupõe, portanto, ao lado da habilidade de se ter ideais morais e da fantasia moral, a capacidade de transformar o mundo das percepções sem violar o contexto determinado pelas leis naturais. Essa capacidade é a técnica moral. Ela pode ser aprendida no mesmo sentido em que, de maneira geral, a ciência pode ser aprendida." (Idem: 107)

"O ser humano é exortado a encontrar uma forma adequada para cada tarefa deste mundo. Na medida em que por um lado trata-se de uma tarefa de conhecimento, para a qual o instrumento do pensar está à sua disposição, por outro lado trata-se de uma tarefa da formação, isto é, da 
intervenção da capacidade humana na matéria e nas forças da natureza, mas especialmente também nas condições sob as quais se concretizam a vida e o trabalho em comum, portanto uma tarefa da arte. A potência formativa e o chegar à forma são os dois aspectos da arte que devem ser aplicados no campo social. Os problemas somente podem ser resolvidos por meio do método da arte, compreendida como descrito. Como ser criativo, o ser humano tem a capacidade de atuar criativamente, não somente no âmbito dos tipos de arte tradicionais, mas também de formar artisticamente a estrutura social. Beuys chega a dizer que, sob essa perspectiva, o ser humano criará uma nova Terra, até mesmo um novo futuro planetário." (Zumdick, W: 1995) 13

"A remodelação da natureza, essa remodelação do aspecto mineral, ter-seá cumprido quando nosso tempo na Terra tiver terminado. Então toda a natureza mineral ter-se-á transformado. O ser humano ter-lhe-á dado todo o seu caráter, do mesmo modo como ele dá a uma porção de metal um caráter quando ele, por exemplo, constrói um relógio. Quando então novamente começar um novo ciclo, o reino mineral poderá ser sugado, absorvido". (Steiner, R: 1904)

Isso ocorre, como descreve Rudolf Steiner, não somente na atualidade, mas também no futuro:

\begin{abstract}
"O que o espírito humano formou na matéria, permanece disponível no mundo como força que continua atuante. ... Por exemplo, a catedral gótica de Köln [Colônia] vai um dia desaparecer, mas o fato de os átomos terem estado nessa forma tem uma importância de grande peso. A forma é em si própria o que há de eterno, que continua a atuar na evolução da humanidade, de tal modo como a força viva está na planta, na evolução da natureza. ... O fato de algo ter sido formado tem um valor imperecível, permanente, eterno.

Também os países e todas as outras comunidades dos seres humanos surgem e desaparecem diante de nossos olhos. Mas o que as pessoas construíram em termos dessas comunidades a partir de suas almas, são ideias humanas introduzidas nelas, que possuem valor eterno, significado de atuação eterna. Quando essa espécie humana aparecer novamente sobre a Terra sob nova forma, então ela enxergará os frutos desses elementos de valor eterno.

Quem hoje eleva o olhar para o céu estrelado, observa uma harmonia maravilhosa. Essa harmonia desenvolveu-se, não esteve sempre lá. Do mesmo modo como colocamos pedra sobre pedra quando construímos uma catedral, como colocamos cor ao lado de cor quando pintamos e estabelecemos lei sobre lei quando organizamos comunidades, assim também trabalharam antigamente seres formadores no que hoje se nos apresenta como cosmos." (Steiner. R. 1906)
\end{abstract}

Aqui se trata de cada pessoa como indivíduo. Você e eu como criadores de uma forma social. Não artistas no sentido tradicional, que realizam sua ideia, mas artistas que têm consideração pelo seu material. Reconhecer no outro uma pessoa como um material com mesmos direitos e ao mesmo tempo a si próprio como material, mas também incluir aquele que está longe de mim, por exemplo a pessoa que vive na África, como alguém com os mesmos direitos, em busca da liberdade. $\mathrm{O}$ 
mesmo vale para a aceitação frente aos reinos da natureza abaixo de mim. Os reinos da natureza como base para minha existência e a do meu próximo. Isto é, como lido com essas bases? Como aplico os recursos que me foram transmitidos e como permito o outro compartilhar deles?

\begin{abstract}
"Somente o Cristo, dentre todos os filósofos, magos etc., assegurou como certeza fundamental a vida eterna, a infinitude do tempo, a nulidade da morte, a necessidade e legitimidade de uma calma feliz e da abnegação. Ele viveu numa calma feliz, como o maior de todos os artistas, desdenhando o mármore, a argila e a cor, trabalhando na carne vivente. Isto é, esse artista inaudito, quase incompreensível, para o instrumento apático de nossos cérebros nervosos e embotados, não criou estátuas, pinturas, livros ... Ele afirmou-o em alto e bom tom, que ele fez ... seres humanos vivos, imortais.

Esse grande artista também não produziu livros... Essas palavras faladas, que ele, como um nobre esbanjador, nem se importou em escrever, constituem um dos mais altos pináculos atingidos pela arte, que aqui tornase força criadora, pura potência criadora. Essas observações, caro colega Bernard, levam-nos longe, muito longe, chegando mesmo a nos elevar por sobre a arte. Elas nos permitem presumir a arte de dar forma à vida, a arte de sermos eternamente vivos." (Van Gogh;1888)
\end{abstract}

Como podemos criar essa "nova Terra", esse novo futuro planetário, sem que eu abandone o desenvolvimento da minha própria personalidade, que reconheço necessário, sem ferir a igualdade do outro, e ao mesmo tempo agir fraternalmente?

Por meio de uma técnica moral e uma fantasia moral conseguimos avançar para dentro das áreas que permanecem cerradas em uma abordagem racional.

Na convivência diária confrontamo-nos continuamente com nossas próprias imperfeições. Agimos egoisticamente, muitas vezes de maneira inconsciente, ou queremos nos ver aprovados pelos outros e deixar o nosso Ego ser servido.

Também posso encarar minha vida como escultura, no entanto ela deve ser uma escultura convincente em relação ao todo. Também posso encarar a família ou um empreendimento como escultura; trata-se de uma tarefa da arte. Cada ser humano como um artista, como tarefa e determinação da natureza. No entanto, devo liberar-me de uma falsa autoridade e ditadura, devo descobrir, como eu ou nós podemos formar e dirigir nossa vida num mundo comum. O trabalho com a escultura social demanda o ser humano total, como artista e como observador, simultânea e 
reciprocamente. É uma questão de atitude. "Trabalha-se com um material realmente vivo. As pessoas são a bomba de mel ['Honigpumpe'], o local de trabalho."”

Aqui estamos bem no começo dessa obra de arte a ser criada. Não se sabe por onde começar e onde terminar. "A arte é uma sublime filha da liberdade." (Schiller. F) ${ }^{\mathrm{vi}}$. O que corresponde a mim? Onde posso desenvolver meu potencial? O que vivencio como realidade? O que percebo, o que reconheço ou imponho em ideologias? É bom não saber nada, estar no ponto zero. "Liberdade é o pré-requisito necessário para se desenvolver o amor, que é o verdadeiro objetivo do desenvolvimento terreno. Disso resulta a máxima fundamental do ser humano livre: viver no amor para com a ação e deixar viver na compreensão do querer do outro". (R.Steiner: 1988, 92)

\section{O ser humano oriental e o ocidental e o direito da mão terra}

No encontro com a mãe Terra, nosso corpo, a nostalgia - como descrito por Caspar David Friedrich - jamais atingida, essa permanece. Somente o ser humano oriental não consegue compreender a nostalgia, pois ele não a tem, não a conhece. Ele tem um acesso direto à Terra, não é separado dela.

\footnotetext{
"O oriental não tem nenhum senso para a comprovação. Ele vivencia em contemplação o conteúdo de suas verdades e por isso as conhece. E o que se sabe, não se comprova. O ocidental demanda provas para tudo. Ele luta, pensando, para atingir o conteúdo de suas verdades a partir do reflexo exterior e assim as interpreta. Mas aquilo que é interpretado deve ser provado. Se o ocidental redimir a vida da verdade a partir de suas provas, o oriental o compreenderá. Se no final do afã de comprovação do ocidental o oriental puder encontrar os seus sonhos de verdade não comprovados, num verdadeiro despertar, então o ocidental terá que saudá-lo como um companheiro no trabalho para o progresso humano, capaz de realizar aquilo que ele próprio não consegue." (Steiner, R. 1922)
}

Trata-se do caminho e ao mesmo tempo do objetivo. Como esclareço a um ocidental a necessidade de encontrar o oriental. O agricultor, se ainda trabalha com o solo, tem um outro relacionamento para com a terra, mais direto. O consumidor já perdeu há muito esse relacionamento. Ele não compreende a linguagem do agricultor ainda ligado à terra; para ele a terra é suja, não viva. No máximo ele compreende essa linguagem como poesia, romantismo ou teoria. 
O agricultor é talvez o último oriental do ocidente, pelo menos o agricultor que ainda trabalha junto à terra. O agricultor que coloca em seus campos preparados dinamizados [da agricultura biodinâmica], é um xamã moderno, um mágico, cujos produtos Ihe dão a segurança para seus rituais. Ele conhece a força do encontro.

\begin{abstract}
"Em nosso tempo devemos reconhecer que sem o direito da mãe Terra não há direitos humanos. No momento em que nós reconhecemos isso, estabelece-se um laço sagrado entre ser humano e Terra. Um laço que se encontra nas cosmologias espirituais de várias culturas. Atingimos uma época empolgante se, no caminho para um novo estado de consciência, podemos renunciar aos velhos cismas entre norte e sul, entre produtores e consumidores e entre agricultores e cientistas. Nesse processo, a Terra é o fundamento da nova civilização. ... A fazenda ou sítio são os últimos redutos da liberdade. Eles podem tornar-se um local para a formação do ser humano; isso depende de nós." (Shiva, V. 2011)

"Qual missão tem a arte em relação ao desenvolvimento espiritual da humanidade? A mesma que outras atividades. Ela ajuda a transformar o mundo todo em uma obra de arte, mesmo se cada obra de arte acaba por desaparecer. No entanto, podemos perguntar se essas obras de arte individuais não têm algum significado, e devemos então, do ponto de vista teosófico [antroposófico], dizer que em uma tal obra de arte ocorrem dois aspectos a serem considerados. Em primeiro lugar, a obra de arte no espaço, e em segundo a força do ser humano que nela atuou. A força do ser humano é o que permanece. A arte significa algo que tem um significado ainda muito maior." (Steiner: 1905)
\end{abstract}

Assim como a planta já contém em si o germe daquilo que ela será no próximo ano, assim o ser humano deve portar em si mesmo o futuro como seu germe, e ele não consegue fazer com que esse último fique suficientemente pleno de conteúdo, suficientemente grande. Isso tem sua aplicação também no presente imediato.

Quando começamos a encarar o mundo não mais como um grão de poeira no universo, mas como uma semente de uma planta que quer germinar, cheia de futuro, alcançamos possibilidades totalmente novas. Devemos aceitar apenas que somos nós que criamos uma boa base para o germinar da semeadura. O que seria uma tal base? Temos que começar a compreender, a aprender, principiar a entender o mundo como uma escola, como uma oficina para o futuro. "E as oficinas somos nós todos juntos." (Hurter, U: 2011) Tudo pode se tornar escola, oficina cultural, só não podemos esquecer o outro nesse processo, esquecer para quem fazemos isto 
ou aquilo. Trabalho é sempre trabalho produzido para outras pessoas. Uma escola Waldorf, um banco alternativo, uma CSA são todos campos para se aprender algo. "Basicamente, todos os movimentos e anseios democráticos, para se libertar de autoridade falsa e ditadura consistem justamente nesse impulso de descobrir como podemos formar e conduzir nossa vida em um mundo em conjunto." (Sacks, S: 2011)

Não podemos perder de vista o objetivo e não esquecer a Lei Social Principal formulada por Rudolf Steiner: "O bem estar [das Heil] de uma comunidade de pessoas que trabalham em conjunto é tanto maior quanto menos cada um reivindicar para si os frutos de seu trabalho, isto é, quanto mais ele der esses produtos aos seus colegas, e quanto mais suas próprias necessidades forem satisfeitas não pelo que ele produziu, mas pela produção dos outros." (Steiner, R: 2007)

\begin{abstract}
"Em uma comunidade de pessoas, todos as organizações [Einrichtungen] que contradizem essa lei devem, a longo prazo, resultar em miséria e necessidade. Essa Lei Principal vale para a vida social com tanta exclusividade [isto é, com uma certa área de aplicação] e necessidade como qualquer lei da natureza em relação a um campo determinado de suas atuações. No entanto, não se deve pensar que é suficiente aplicar essa lei como algo moral geral, ou querer convertê-la no sentido que cada um deva trabalhar para seus colegas. Não, na verdade essa lei somente vive como deveria viver, se uma comunidade de pessoas consegue criar organizações de tal modo que nunca alguém possa reivindicar para si mesmo os frutos de seu próprio trabalho, mas que estes, sem deixar restos, revertam em favor da comunidade. Em contrapartida, essa própria pessoa deve manter-se por meio do trabalho de seus colegas. Portanto, o que importa é que trabalhar para os colegas e visar um certo rendimento são duas coisas totalmente separadas uma da outra." (Idem: 2007)
\end{abstract}

Aqui eu preciso, no entanto, uma relação profunda para comigo próprio, para meu ego, para meu egoísmo. Uma fazenda, minha fazenda, pode tornar-se um local que pode levar-me a essas relações. Ele pode me mover a agir,

"um agir que depende de uma consciência comum. ... Se conseguirmos
criar uma consciência com os consumidores e o meio ambiente, onde todos
participantes atuam a partir da percepção das condições, da situação geral,
e não apenas a partir do interesse pessoal, portanto, não a partir da
consciência do ego. ... Como se forma a relação com o consumidor? Será
que isso acontece apenas por meio dos produtos? Esse é apenas um
primeiro nível de relacionamento. Um segundo nível se dá mediante a
vivência. Os consumidores visitam a unidade agrícola e lá vivenciam algo.
Ainda há um terceiro nível, onde não há apenas a vivência, mas onde
ocorre um processo de percepção. Nesse caso não estamos apenas numa 
observação de resultados, mas num diálogo, numa conversa, onde cada um começa a se ver a partir do contexto total. O quarto nível seria uma unidade agrícola como um local de calma, onde me aproximo das minhas mais profundas fontes - quem eu realmente sou. Então ocorre uma expansão da consciência, um aprofundamento. Aí eu noto quem eu realmente sou, e para que estou aqui. Quando desperto para um plano mais profundo de mim próprio, trata-se de algo onde eu chego a impulsos de atuação comuns. De fato, um diálogo oferece mais do que aprender. Aqui a inspiração vem de uma comunidade supra-pessoal." (Scharmer, C.-O: 2011)

Se isso é arte, devemos, por fim, colocar no centro o ser humano como material a ser trabalhado. Trazer a arte para fora dos museus e colocá-la entre as pessoas como material pedagógico e terapêutico. Não fixar a vista no material, mas participar dele. Entre o observador e o objeto surge um terceiro elemento. Entre pessoas surge movimento, calor, algo que se abre, troca de ideias. A pessoa quer descobrir-se como ser humano.

\begin{abstract}
"Quando temos uma obra de arte, o espiritual brilha através dela. Assim, a obra de arte não se nos apresenta como uma necessidade férrea, mas como uma aparência, que expressa para nós o que é ideal, espiritual. No belo o espírito e a sensorialidade estão equilibrados. Espírito e sensorialidade também devem estar em equilíbrio no ser humano. ... Onde a pessoa se encontra entre esses dois estados, onde ela não depende da necessidade física nem da lógica, mas onde vive em um estado denominado por Schiller de estético, supera-se a paixão. Ela trouxe o espírito até si, purificou a sensorialidade por meio do belo. Assim, a pessoa tem o impulso e o desejo de, voluntariamente, fazer o que exige o imperativo categórico [conceito introduzido por Kant]. Então a moralidade do ser humano é algo que nele se tornou carne e sangue, de modo que os impulsos e desejos manifestam eles próprios o espiritual. Desse modo o espírito e a sensorialidade permearam o ser humano estético, espírito e sensorialidade permeiam-se no ser humano, porque ele ama o que ele deve fazer. O que está adormecido no ser humano deve ser despertado. ... Também a respeito da sociedade, das leis, as pessoas serão forçadas a conviver conforme a lei partindo da necessidade ou do Estado racional. Entre ambos encontra-se a sociedade estética, onde o amor realiza o anseio que existe de pessoa para pessoa, e lhe é imposto por sua mais íntima tendência. Então, para sua convivência, as pessoas não necessitam de leis exteriores que regulem a convivência, na sociedade estética as pessoas atuam livremente em conjunto, não necessitando de leis exteriores. Elas mesmas são a expressão das leis, segundo as quais as pessoas devem conviver. Linda e sublime é essa sociedade descrita por Schiller, onde as pessoas convivem em amor e afeição recíproca, fazendo em liberdade o que elas devem e precisam fazer." (Steiner, R: 1905)
\end{abstract}

Se conseguirmos unir espírito e sensorialidade dentro de nós e no mundo, essas duas correntes, da comprovação e do encontro direto, teremos os melhores pré-requisitos para formar uma verdadeira escultura social. Um terceiro elemento acrescentarse-á, para representar uma região intermediária. São os três reis do 
"conto" de Goethe (1795) 29, que anunciam uma trimembração do organismo social. O quarto rei deve morrer, para dar lugar a um novo estado planetário.ii

Se conseguirmos elaborar de um modo plástico social esse espaço, que os pintores de paisagens do séc. XIX nos prometeram como imagens de um outro mundo, então conseguiremos tornar vivencial esse mundo. Não se trata de um espaço de vivências no qual se pode caminhar, para fugir dos centros urbanos, mas para atingir uma verdadeira obra de arte conjunta.

\footnotetext{
Notas

${ }^{i}$ As datas precisas indicam as datas das palestras dadas por R. Steiner, precedidas da cidade onde foram proferidas. As obras originais de Steiner estão disponíveis em http://fvn-rs.net. As citações foram traduzidas diretamente do artigo original, e não copiadas das traduções publicadas

ii Mateus 18:20

iii Joseph Beuys. "Cada pessoa é um artista. Com isso, eu não afirmo nada sobre a qualidade. Estou apenas dizendo algo sobre a possibilidade que jaz em princípio em cada pessoa."

iv Van Gogh a Émile Bernard, Arles, junho/julho de 1888.

${ }^{\vee}$ Beuys zur Honigpumpe am Arbeitsplatz [Beuys sobre a instalação "Bomba de mel no local de trabalho"], 1977 [ver http://de.wikipedia.org/wiki/Honigpumpe_ am_Arbeitsplatz].

vi Schiller. F. Op. cit. 2a carta.

${ }^{\text {vii }}$ Rudolf Steiner descreve as relações entre as cartas de Schiller e o conto de Goethe em Die neue Geistigkeit und das Christus-Erlebnis des zwanzigsten Jahrhunderts [A nova espiritualidade e a vivência do Cristo do séc. XX], GA 200, $4^{\mathrm{a}}$ palestra, Dornach, 24/10/1920.
}

\section{Referências Bibliográficas}

CRAEMER, U. Favela Monte Azul, p. 67. Stuttgart: Verlag Freies Geistesleben, 1987.

GOETHE, J.W. von. Das Märchen von der grünen Schlange und der schönen Lilie [O conto da Serpente Verde e da Bela Flor de Lis], 1795 [O conto da serpente verde e da linda Lilie. São Paulo: Landy Editora].

HURTER, U. Eröffnungsrede für die Landwirtschaftliche Tagung [Discurso de abertura para o congresso de agricultura]. Dornach: 2011

SACKS, S. Soziale Plastik heute [A plástica social hoje]. Oya, Zeitschrift für den gesellschaftlichen Wandel [Oya, revista para a mudança social], 9/2011

SCHARMER, C.-O. Landwirtschaftliche Tagung [Congresso agrícola]. Dornach, 2011. 
SCHILLER, F. Über die Ästhetische Erziehung des Menschen, 14. Brief [A Educação Estética Do Homem, 14a carta. São Paulo: Ed. Iluminuras ].

STEINER, R. Die Philosophie der Freiheit, 1894. GA [Obra completa No.] 4 [A filosofia da liberdade, trad. A. Grandisoli. São Paulo: Ed. Antroposófica 1988; o trad. não recomenda a outra tradução da mesma editora].

Ausführungen Rudolf Steiners über Wesen und Bedeutung von Schillers Ästhetischen Briefen, p. 148 [Considerações de Rudolf Steiner sobre a essência e significado das Cartas Estéticas de Schiller]. Stuttgart: Verlag freies Geistesleben, 1989.

Wie wirkt man für den Impuls der Dreigliederung des sozialen Organismus? [Como atuar para o impulso da trimembração do organismo social?] GA 338, Stuttgart 15/2/1921, palestra da tarde

Die Tempellegende und die goldene Legende [A lenda do templo e a lenda áurea], GA 93, Berlin, 2/1/1906.

Die Tempellegende und die Goldene Legende, Berlin, 9/12/1904.

R. Westliche und östliche Weltggensätzlichkeit (West-Ost-

Kongress) [Qualidades universais opostas ocidentais e orientais (Congresso Oeste-Leste)], GA 83, Viena 1-12/6/1922.

"Die Zukunft des Menschen" [O futuro do ser humano] in Ursprung und Ziel des Menschen [Origem e objetivo do ser humano], GA 53, Berlin, 30/3/1905.

Geisteswissenschaft und soziale Frage [Ciência espiritual e questão social], in GA 34, 1905 [Economia e Sociedade à luz da Ciência Espiritual. São Paulo: Ed. Antroposófica, 3a. ed. 2007].

"Schiller und die Gegenwart" [Schiller e o presente], in Ursprung und Ziel des Menschen [Origem e objetivo do ser humano], GA 53, Berlin, 4/5/1905.

ZUMBLICK, W. Über das Denken bei Joseph Beuys und Rudolf Steiner [Sobre o pensamento de Joseph Beuys e Rudolf Steiner]. Basel: 1995.

SHIVA, V. Landwirtschaftliche Tagung [Congresso de agricultura]. Dornach: 2011. 